\title{
Dream Lucidity is Associated with Positive Waking Mood
}

\author{
Abigail Stocks ${ }^{\mathrm{a} 1}$ \\ Michelle Carr ${ }^{\mathrm{a}}$ \\ Remington Mallett ${ }^{\mathrm{b}}$ \\ Karen Konkoly ${ }^{\mathrm{c}}$ \\ Alisha Hicks ${ }^{\mathrm{a}}$ \\ Megan Crawford ${ }^{\mathrm{d}}$ \\ Michael Schredl ${ }^{\mathrm{e}}$ \\ Ceri Bradshaw ${ }^{\mathrm{a}}$
}

${ }^{a}$ Swansea University, Department of Psychology, Swansea, UK

${ }^{\mathrm{b}}$ University of Texas at Austin, Department of Psychology, TX, USA

${ }^{c}$ Northwestern University, Department of Psychology, IL, USA

d University of Strathclyde, Glasgow, UK

e Central Institute of Mental Health, Medical Faculty Mannheim/Heidelberg University,

Mannheim, Germany

*Authors with equal contributions

${ }^{1}$ Corresponding author: Michelle_Carr@urmc.rochester.edu; Current Address: University of Rochester, Department of Psychiatry, Rochester, NY 


\begin{abstract}
Lucid dreaming is a unique phenomenon with potential applications for therapeutic interventions. Few studies have investigated the effects of lucidity on an individual's waking mood, which could have valuable implications for improving psychological wellbeing. The current experiment aims to investigate whether the experience of lucidity enhances positive waking mood, and whether lucidity is associated with dream emotional content and subjective sleep quality. 20 participants were asked to complete lucid dream induction techniques along with an online dream diary for a week, which featured a 19-item lucidity questionnaire, and subjective ratings of sleep quality, dream emotional content, and waking mood. Results indicated that higher lucidity was associated with more positive dream content and elevated positive waking mood the next day, although there was no relationship with sleep quality. The results of the research and suggestions for future investigations, such as the need for longitudinal studies of lucidity and mood, are discussed.
\end{abstract}

Keywords: lucid dreaming; positive mood; REM sleep; nightmares 
Dream Lucidity is Associated with Positive Waking Mood 


\section{INTRODUCTION}

Lucid dreams are an insightful and curious phenomenon, defined as dreams in which an individual becomes consciously aware that they are dreaming. Lucid dreamers are immersed in a 'hybrid' state of consciousness, which features elements of both reality and dreaming (Voss et al., 2009). As a result, dreamers can sometimes change the dream scene or situation and manipulate dream events as they desire. As the dream world is not bound by the laws or parameters of physical waking life, individuals are able to perform acts such as flying, magic or breathing underwater; behaviours that are impossible in the real world (Stumbrys \& Erlacher, 2016). A recent meta-analysis comprised of 50 years of empirical research states that $55 \%$ of the individuals studied had experienced at least one lucid dream (LD) in their lifetime, with half of these reporting monthly or more frequent occurrences (Saunders, Roe, Smith \& Clegg, 2016), thus indicating that lucidity is common among the population. The general consensus surrounding the literature on lucid dreaming is that it mainly occurs during REM sleep (LaBerge, Nagel \& Dement, 1981; Scarpelli et al., 2019; Zadra \& Pihl, 1997); the first objective verification of lucid dreams came from experiments where lucid dreamers were able to indicate they were lucid by performing a specific pattern of eye movements during REM sleep, which researchers observed using electrooculography (Laberge et al., 1981; Hearne, 1978).

The growing investigation into lucid dreaming has led to a number of potential applications for the phenomenon. For those who suffer bad dreams or nightmares, learning to lucid dream can be used as a therapeutic tool. Nightmares are dreams that elicit strong negative emotions of fear, sadness, anger or disgust that cause night-time awakenings (Zak et al., 2010; Gieselmann et al., 2019). Nightmares are particularly troubling as they tend to increase arousal and interrupt sleep, with sufferers often struggling with increased sleep latency (problems falling to sleep), or being repeatedly awakened due to re-experiencing nightmares throughout the sleep period (Zak et al, 2010). Unsurprisingly, higher nightmare frequencies have been linked to low levels of psychological wellbeing (Zadra, 1996). Nightmares are known to cause immediate and negative impacts on waking mood, termed nightmare distress (Belicki et al., 1992).

With lucid dreaming, individuals have the potential to alter their bad dreams or nightmares so that they are less frightening, perhaps giving the dreamer an increased sense of control and 
empowerment over something that was previously regarded as beyond their capabilities (Mota-Rolim \& Araujo, 2013). There is a promising body of research that indicates that nightmares can be reduced in both frequency and intensity by teaching individuals to lucid dream (Zadra \& Pihl, 1997; Spoormaker \& van den Bout, 2006). Furthermore, an online survey conducted by Stumbrys and Erlacher (2016) found that in the general population, selfreported lucid dreamers $(n=386)$ use lucid dreams to overcome fears experienced during nightmares, fulfil wishes for waking life and help both emotional and physical healing, indicating the positive impact of lucid dream experience on waking mood across a large population.

The experience of positive dreams in general may lead to more positive waking mood the subsequent day, an effect analogous to the distress caused by nightmares (Carr \& Nielsen, 2017). Results have shown that positive dream affect correlates with waking peace of mind (Sikka, Pesonen \& Revonsuo, 2018) and dream mindfulness (similar to lucidity) predicted increases in self-reflection following sleep (Lee \& Kuiken, 2015); in the latter study, transcendent dreams were also associated with reported spiritual transformation, although such effects likely vary across individuals. Other research has found that impactful dreams, characterized by a heightened sense of reality and engagement in a vivid dream, can be associated with deepened self-perception after awakening (Kuiken, 1995). Thus, cultivating positive dream experiences may constitute a worthwhile intervention, either to counteract the negative effects of nightmares, or to improve self-reflection, well-being or mood in general populations. It is worth noting that the experience of positively valanced dreams has been linked with a better quality of sleep (Agargun et al., 2004), highlighting potential physical benefits of pleasant dreams. Lucid dreams tend to feature more positive emotional content than regular dreams, and lucid dreamers often use their dreams to have fun (Schädlich \& Erlacher, 2012). Some research has linked lucid dreaming with an increase in positive mood (Konkoly \& Burke, 2019), for instance when the individual chooses to fulfil waking life wishes whilst lucid dreaming (Stumbrys \& Erlacher, 2016). However, there is little empirical work on the duration of positive impacts of lucid dreaming on waking mood. It is possible that positive dreams can have cumulative beneficial impacts on well-being over time, in contrast to the detrimental impacts of nightmares and nightmare distress on psychopathology. Given the potential of lucid dreaming as a psychological intervention, further research measuring dream lucidity, positivity, and assessing the immediate and long-term impact on mood is necessary. 
Nevertheless, it should be noted that some authors highlight that evidence related to lucid dreaming as a therapy is limited, mixed or low quality (Zak et al., 2010; Macêdo et al., 2019). One recent study showed that dream content control, even when lucid, was difficult for the majority of PTSD patients to achieve (Harb et al., 2016). In addition, some researchers state that deliberate lucid dream induction can have negative consequences, such as increased psychopathology and sleep disturbances (Aviram \& Soeffer-Dudek, 2018), leaving them to conclude that induction carries long-term physical and psychological risks. This points to the need for increased research concerning the outcomes of using lucid dreams as an intervention, and the necessity to further explore the consequences of lucidity in the general population.

In order to study dream lucidity, a variety of relatively simple cognitive techniques can be used to increase likelihood of lucid dreaming (Stumbrys, Erlacher, Schädlich \& Schredl, 2012; Aspy, Delfabbro, Proeve \& Mohr, 2017). One of the methods, known as reality testing (Tholey, 1983; LaBerge \& Rheingold, 1991), involves an individual taking a few moments throughout the day to genuinely consider whether they are in a dream or not; the expectation is that habitual reality testing during the day will increases the likelihood that a dreamer will test their dream surroundings, and realize that they are asleep and in a dream. Two other methods, the Mnemonic Induction of Lucid Dreams (MILD; LaBerge, 1980) and WakeBack-To-Bed (WBTB; LaBerge, Phillips \& Levitan, 1994) techniques, are used in conjunction with each other, in that an individual is awoken from sleep after a specific time period to increase mental alertness (WBTB) and instructed to cognitively rehearse a phrase, such as 'I will remember I am dreaming' (MILD) whilst falling back to sleep. It is more likely that REM sleep will be entered quickly after early morning awakenings (Scarpelli et al., 2019), further increasing the chances of lucid dreaming. Aspy et al., (2017) found that combining reality checks with the WBTB and MILD techniques was better for lucid dream induction than reality testing alone. It was concluded by the researchers that using the three techniques collectively would be the most effective way to increase dream lucidity.

Although lucid dreaming has been associated with REM sleep (LaBerge, Nagel \& Dement, 1981), recently researchers have cautioned that practicing lucid dream induction techniques may be associated with sleep disruption (Soffer-Dudek, 2020). Thus, further assessments of objective sleep measures within lucid dreaming studies is warranted. With the recent 
development of novel wearable devices for measuring sleep at home, the current research aimed to pilot and investigate a possible link between lucid dreams and REM sleep as measured by a portable headband (Hypnodyne ZMax). Mota-rolim et al. (2019) claim that ZMax is the only research-ready lucid dreaming headband available on the market, although it has not been empirically assessed to date. The headband uses disposable hydrogel electrode patches with two frontal sensors that capture EEG activity and eye movements, and includes a hardware box with a sensor for heart rate, temperature, light, sound and body movements. The signal can be recorded to an internal memory card and scored offline, or it can be wirelessly connected to a computer for online REM sleep detection. The automatic detection is unique in that after a two hour delay, the software analyzes the first 2 hours' data and creates a phenotype of the individual, in order to better detect the individual's REM epochs. As an initial pilot of this equipment we here recruited a small sample of participants to wear the headband offline and record objective sleep measures to its internal memory card, during a week of practicing lucid dream induction techniques at home.

The current experiment aimed to investigate the relationship between lucidity, dream emotional content, and positive waking mood. We hypothesised that those who experienced higher levels of dream lucidity would report more positive waking mood and positive dream content. We utilized the methods of Aspy et al. (2017), combining reality-testing, WBTB and MILD techniques daily for 7 days, given their effectiveness for increasing dream lucidity. We hypothesized that the extent to which participants practiced the induction techniques would be correlated with levels of lucidity. Finally, we piloted the use of portable headbands to explore whether lucid dreaming corresponded with objective sleep measures; it was hypothesized that higher lucidity would be associated with longer REM sleep duration.

\section{METHODS}

\subsection{Participants}

The sample for this research consisted of 20 persons (males $n=8$, females $n=12$ ) aged 21-33 years $(\mathrm{M}=24.6, \mathrm{SD}=2.93)$. An initial screening questionnaire with two dream items assessed participants' baseline dream recall frequency per last week $(\mathrm{M}=3.1, \mathrm{SD}=1.77)$ and $\mathrm{LD}$ recall frequency per last month $(\mathrm{M}=1.8, \mathrm{SD}=2.61)$.

\subsection{Materials}

\subsubsection{Lucid induction techniques}


The reality check method involved a participant taking a few moments out of their day to genuinely contemplate whether they are dreaming or not. The instructions were as follows:

"A reality check is when you take 10-30 seconds away from your current activities, and ask yourself honestly the question "Am I dreaming?" For example, take a few moments to look around and evaluate whether everything is in accordance to the physical laws of waking life."

This could be achieved by asking the question internally and/or checking their surroundings for physical markers that would indicate they are awake, such as that the environment is remaining constant and not spontaneously shifting as it does in a typical dream state. For the MILD/WBTB method, participants were asked to set an alarm for 5 hours after going to bed. They were then asked to fully wake up, turn on the light and perform a reality check. Following this, they were asked to go back to sleep repeating a phrase in their mind, such as "when I am dreaming, I will remember I am dreaming". They were asked to continue to repeat the phrase until the intention was set or until they fell back to sleep. Participants were asked to complete the reality check and MILD/WBTB techniques on a daily basis for 7 days. In the morning, participants completed an online survey and reported how many reality checks they performed on the previous day and how many minutes of MILD they performed during the night.

\subsubsection{Sleep and dream diary}

Participants were asked what time they went to bed and woke up, and rated their sleep quality on a scale of 0 (poor) to 7 (excellent). Participants were then asked to fill in a dream report using an open text box, with instructions to refer to any thoughts, feelings or sensations they experienced. Participants then rated the intensity of 8 dream attributes: this included 1 item rating sensory vividness of the dream; 1 item rating dream bizarreness; 3 items rating negative content (negative intensity, negative sensations, and negative impact of the dream), and 3 items rating positive content (positive intensity, positive sensations, and positive impact of the dream). Each item was rated on a Likert scale from 1 (very little) to 9 (a lot) of the attribute, and there was also an option for 'no recall' if a participant could not remember anything. The rating scales have been used in earlier empirical studies and found to be sensitive to sleep stage of dream recall (Carr \& Nielsen, 2015) and habitual dream and nightmare recall (Carr et al., 2016).

\subsubsection{Lucidity questionnaire}


The main lucidity measure was a 19-item questionnaire relating to lucid experiences during the reported dream. This 19-item questionnaire was a composite of all of the items from the Dream Lucidity Questionnaire (Stumbrys, Erlacher \& Schredl, 2013) and the Lucid Skills Questionnaire (Schredl, Rieger \& Goritz, 2018); between the two questionnaires there are 4items that overlap, 9 questions unique to the DLQ and 6 questions unique to the LUSK. For all items, participants were asked to rate the extent to which they agreed with the statements, from 0 (not at all) to 4 (very much). Some examples of these statements are as follows: 'I was aware my physical body was asleep', 'I deliberately decided to observe the dream as a dream', 'I clearly remembered my intention of what I wanted to do in a LD', 'I had full control of my dream body/actions' and 'I changed the dream scene in the way I wanted'. Participant's lucidity level was calculated as an average daily score on the lucidity questionnaire.

Participants were also asked open-ended questions about why they rated their awareness at the level chosen, but these qualitative responses are not analysed here.

\subsubsection{Waking mood}

Following the lucidity questionnaire, the PANAS (Watson et al., 1988) scale was used to measure participants' mood state each morning. The PANAS lists several positive and negative emotional states, such as interested, irritable, excited, distressed, active or hostile, among others. Participants rate on a scale how much they currently feel these emotions, ranging from 1 (very slightly or not at all) to 5 (extremely). The Positive Affect Scale reliability is moderately good, with Cronbach alpha of 0.86 to 0.90; the Negative Affect Scale Cronbach alpha is 0.84 to 0.87 .

\subsubsection{Sleep recording}

In addition, to the daily diaries, participants were asked to wear portable headbands (Hypnodyne ZMax) each night. This required placing an electrode patch on the forehead, which has two EEG/EOG sensors at approximately F3/F4 and records data to an internal microSD card for up to 8 nights. Participants were also required to charge the devices daily, with a typical battery life of $\sim 10 \mathrm{hrs}$. Our objective measures were calculated from the headband data; the variables of total sleep duration, minutes of Wake After Sleep Onset (WASO), minutes of REM sleep, and minutes of NREM sleep stages 1, 2, and 3 (Hypnodyne ZLab analysis software). Experimenters completed visual inspection of the headband data prior to analysis to check for poor recording quality or periods of electrode disconnection, in 
which case the data was excluded. ZLab analysis software uses proprietary phenotype detection and scoring algorithms to automatically detect sleep stages. Zlab has not yet been validated in comparison to in-laboratory polysomnography with standard American Academy of Sleep Medicine scoring of sleep stages (Berry et al., 2012).

\subsection{Procedure}

Subjects complete an initial questionnaire on dreaming and were invited to the laboratory to participate. Participants completed Informed Consent (Ethics approved by the Psychology Department of Swansea University). The researcher explained the reality check and MILD/WBTB techniques with the participant so that they were clear on carrying out the methods independently. The researcher assisted the participants with fitting the portable headband and showed them how to operate and charge the device. The rest of participation was based in participants' own homes for 1 week, during which they were asked to complete around 10 reality checks daily alongside the MILD/WBTB technique on a nightly basis. Participants were asked to complete a dream diary and online questionnaires every morning relating to induction technique practice, sleep quality, dream vividness, lucidity, and waking mood using the Positive and Negative Affect Schedule (PANAS; Watson et al., 1988). Participants were also required to wear the headband each night to record their sleep. Participants were awarded $£ 15$ for 1.5 hours of participation, as the set-up of the sleep recording and completion of the relevant online questionnaires required approximately 10 minutes of participant time per day, for 7 days.

\subsection{Strategy for Data Analysis}

A between-subjects analysis was conducted to investigate differences between high and low lucidity groups for self-report data. We first median split participants according to average weekly score on the lucidity questionnaire, into a low and high lucidity group, and conducted independent t-tests between groups on all self-report data. We also conducted Pearson's correlations between average weekly lucidity score and all variables.

A within-subjects analysis was then conducted to investigate differences between a participant's highest and lowest lucidity nights for both self-report and objective sleep data. We selected participants' highest and lowest lucidity night, and compared self-report data collected for the two nights using paired-samples t-tests. We also conducted Pearson's correlations between lucidity score and self-report data for the high lucidity night. Finally, we compared objective sleep measures between participants' highest and lowest lucidity nights. 


\section{RESULTS}

\subsection{Between-Subjects Comparison (High Lucidity vs Low Lucidity Groups)}

Those participants who reported no dreams during the experiment $(n=4)$ were first excluded from all analyses. The remaining participants had a baseline dream recall frequency $(\mathrm{M}=3.44$, $\mathrm{SD}=2.61)$ and $\mathrm{LD}$ per last month $(\mathrm{M}=2.00, \mathrm{SD}=2.76)$. For a between-subjects analysis, the data was separated into a High Lucidity group $(n=8)$ and a Low Lucidity group $(n=8)$ using a median split according to their lucidity score. The descriptive and inferential statistics for each outcome measure are shown in Table 1. For these analyses, one participant in the Low Lucidity group was missing data for amount of induction technique practice.

Table 1. Descriptive and Inferential Statistics for Between-Subjects Self-Report Data (High (n=8) vs Low Lucidity (n=8) Groups)

\begin{tabular}{|c|c|c|c|c|c|c|}
\hline $\begin{array}{l}\text { Outcome } \\
\text { Measure }\end{array}$ & $\begin{array}{c}\text { Low } \\
\text { Lucidity } \\
\text { Group }\end{array}$ & $\begin{array}{c}\text { High } \\
\text { Lucidity } \\
\text { Group }\end{array}$ & $t$ & $\mathbf{P}$ & $r$ & $\mathbf{P}$ \\
\hline & $\mathbf{M} \pm \mathbf{S D}$ & $\mathbf{M} \pm \mathbf{S D}$ & & & & \\
\hline $\begin{array}{l}\text { Average } \\
\text { Lucidity }\end{array}$ & $0.25 \pm 0.22$ & $1.40 \pm 0.41$ & -9.114 & $<.001 * *$ & - & - \\
\hline $\begin{array}{l}\text { \#Reality } \\
\text { Checks }^{\mathrm{a}}\end{array}$ & $4.32 \pm 2.62$ & $4.88 \pm 2.70$ & -.405 & .323 & .092 & .746 \\
\hline $\begin{array}{l}\text { Minutes of } \\
\text { MILD }^{\mathrm{a}}\end{array}$ & $2.48 \pm .65$ & $2.99 \pm 1.99$ & -.639 & .534 & -.223 & .425 \\
\hline $\begin{array}{l}\text { Sleep } \\
\text { Quality }\end{array}$ & $4.02 \pm 1.21$ & $4.63 \pm 1.10$ & -1.049 & .319 & .257 & .336 \\
\hline $\begin{array}{l}\text { Negative } \\
\text { Dream }\end{array}$ & $13.48 \pm 6.57$ & $12.71 \pm 4.49$ & .274 & .788 & .118 & .664 \\
\hline $\begin{array}{l}\text { Positive } \\
\text { Dream }\end{array}$ & $9.45 \pm 2.25$ & $13.17 \pm 2.98$ & -2.812 & $.014 *$ & .617 & $.011 * *$ \\
\hline $\begin{array}{l}\text { Sensory } \\
\text { Experience }\end{array}$ & $3.31 \pm 1.35$ & $4.89 \pm 2.98$ & -2.132 & $.051^{\dagger}$ & .733 & $.001 * *$ \\
\hline Bizarreness & $5.33 \pm 2.65$ & $5.95 \pm 1.52$ & -.569 & .578 & .140 & .605 \\
\hline $\begin{array}{l}\text { Negative } \\
\text { Waking }\end{array}$ & $16.50 \pm 6.90$ & $14.81 \pm 2.52$ & .653 & .525 & -.113 & .682 \\
\hline $\begin{array}{l}\text { Positive } \\
\text { Waking }\end{array}$ & $15.35 \pm 4.57$ & $23.98 \pm 10.32$ & -2.162 & $.048 *$ & .649 & $.007 * *$ \\
\hline
\end{tabular}

${ }^{a}$ For induction technique comparisons (\# Reality Checks and Minutes of MILD) $N=7$ in Low Lucidity group due to missing data; ${ }^{\dagger} p<.06,{ }^{*} p<.05,{ }^{*} p \leq .011$ 
Results showed no significant differences between high and low lucidity groups for number of reality checks, minutes of MILD, self-reported sleep quality, negative dream intensity, bizarreness, sensory vividness, or negative waking mood. The high lucidity group had higher positive dream intensity $(\mathrm{p}=.014)$ and positive waking $\operatorname{mood}(\mathrm{p}=.048)$ than the low lucidity group, although these did not survive correction for multiple comparisons (one-tailed Bonferroni correction for 9 tests would require a $\mathrm{p}$ value $<.011$ ).

There were positive correlations between lucidity score and positive dream intensity $(r=.617$, $\mathrm{p}=.011)$, sensory vividness $(\mathrm{r}=.733, \mathrm{p}=.001)$, and positive waking $\operatorname{mood}(\mathrm{r}=.649, \mathrm{p}=0.007)$, all of which survive corrections. There were no other significant correlations.

\subsection{Within Subjects Comparison (High Lucidity Night vs Low Lucidity Night)}

\subsubsection{Self report data}

For a within-subjects analysis, those participants who did not have any variation in lucidity $(n=4)$ were excluded from the analysis. Thus for 12 participants, we selected the highest and lowest lucidity night and compared all self-report data between the two nights. The descriptive and inferential statistics for each outcome measure are shown in Table 2.

Results showed no significant differences for number of reality checks, minutes of MILD, self-reported sleep quality, negative dream intensity, sensory vividness and negative waking mood. However, the highest lucidity night was associated with significantly more positive waking $\operatorname{mood}(\mathrm{p}=.005)$, and more bizarreness $(\mathrm{p}=.037)$, although bizarreness did not survive correction.

In addition, correlations were conducted between lucidity score and all variables, for the Highest Lucidity night. There was a positive correlation between lucidity and positive dream intensity $(p=.009)$, and positive waking $\operatorname{mood}(p=.015)$.

Table 2. Descriptive and Inferential Statistics for Within-Subjects Data (High Lucidity Night vs Low Lucidity Night, $\mathrm{n}=12$ )

\begin{tabular}{|lcclll|}
\hline $\begin{array}{l}\text { Outcome } \\
\text { Measure }\end{array}$ & $\begin{array}{c}\text { Lowest } \\
\text { Lucidity } \\
\text { Night }\end{array}$ & $\begin{array}{c}\text { Highest } \\
\text { Lucidity } \\
\text { Night }\end{array}$ & $t$ & $p$ & $\begin{array}{c}\text { High Lucid } \\
\text { Night } \\
\text { Correlations }\end{array}$ \\
\hline
\end{tabular}




\begin{tabular}{|c|c|c|c|c|c|c|}
\hline & $\mathbf{M} \pm \mathbf{S D}$ & $\mathbf{M} \pm \mathbf{S D}$ & & & $r$ & $\mathrm{p}$ \\
\hline $\begin{array}{l}\text { Lucidity } \\
\text { Average }\end{array}$ & $0.38 \pm 0.30$ & $1.39 \pm 0.77$ & -5.664 & $<.001 *$ & - & - \\
\hline $\begin{array}{l}\text { \#Reality } \\
\text { Check }\end{array}$ & $4.00 \pm 2.56$ & $4.08 \pm 2.43$ & -.143 & .889 & -.004 & .991 \\
\hline $\begin{array}{l}\text { Minutes of } \\
\text { MILD }\end{array}$ & $2.08 \pm 1.98$ & $4.13 \pm 3.25$ & -1.507 & .160 & -.375 & .230 \\
\hline $\begin{array}{l}\text { Sleep } \\
\text { Quality }\end{array}$ & $4.08 \pm 1.56$ & $4.29 \pm 1.29$ & -.418 & .684 & .170 & .597 \\
\hline $\begin{array}{l}\text { Negative } \\
\text { Dream }\end{array}$ & $14.67 \pm 6.57$ & $12.42 \pm 7.75$ & .975 & .350 & .020 & .951 \\
\hline $\begin{array}{l}\text { Positive } \\
\text { Dream }\end{array}$ & $9.50 \pm 3.34$ & $15.17 \pm 7.63$ & -2.184 & $.052^{\dagger}$ & .714 & $.009 * *$ \\
\hline $\begin{array}{l}\text { Sensory } \\
\text { Experience }\end{array}$ & $4.25 \pm 2.18$ & $5.75 \pm 3.08$ & -1.431 & .180 & .439 & .153 \\
\hline Bizarreness & $4.58 \pm 2.68$ & $6.83 \pm 2.48$ & -2.377 & $.037^{*}$ & .266 & .403 \\
\hline $\begin{array}{l}\text { Negative } \\
\text { Waking }\end{array}$ & $17.08 \pm 5.47$ & $16.58 \pm 7.38$ & .214 & .835 & -.368 & .239 \\
\hline $\begin{array}{l}\text { Positive } \\
\text { Waking }\end{array}$ & $16.50 \pm 6.64$ & $25.17 \pm 10.58$ & -3.447 & $.005 * *$ & .678 & $.015 *$ \\
\hline
\end{tabular}

\subsubsection{Objective Sleep Data}

In addition, a within-subjects analysis was conducted on those participants with complete headband data $(n=5)$ for their highest and lowest lucidity night. Seven participants had to be excluded from this analysis due to missing or inadequate headband recordings, or missing dates in the dream diary; these limitations are detailed in the discussion. Due to the large amount of missing data we were underpowered for formal analyses, but we present the descriptive results for each sleep variable as shown in Table 3. Of interest, the amount of REM sleep is nearly twice as high in the highest lucidity night (115.8 \pm 31.72 minutes) compared to lowest lucidity night $(63.2 \pm 38.25)$.

Table 3. Descriptives for sleep Data (High vs Low Lucidity Nights, $n=5$ )

\begin{tabular}{|lcc|}
\hline PSG Measure & $\begin{array}{c}\text { Lowest Lucidity } \\
\text { Night }\end{array}$ & $\begin{array}{c}\text { Highest } \\
\text { Lucidity Night }\end{array}$ \\
\hline & $\mathbf{M} \pm$ SD & $\mathbf{M} \pm$ SD \\
\hline $\begin{array}{l}\text { Total Sleep } \\
\text { Time }\end{array}$ & $414.5 \pm 23.20$ & $442.9 \pm 70.75$ \\
\hline
\end{tabular}




\begin{tabular}{|lcc|}
\hline $\begin{array}{l}\text { Minutes of } \\
\text { REM Sleep }\end{array}$ & $63.2 \pm 38.25$ & $115.8 \pm 31.72$ \\
\hline $\begin{array}{l}\text { Minutes of } \\
\text { Stage 1 Sleep }\end{array}$ & $74.4 \pm 35.65$ & $62.1 \pm 29.33$ \\
\hline $\begin{array}{l}\text { Minutes of } \\
\text { Stage 2 Sleep }\end{array}$ & $168.6 \pm 50.24$ & $165.9 \pm 75.06$ \\
\hline $\begin{array}{l}\text { Minutes of } \\
\text { Stage 3 Sleep }\end{array}$ & $106.7 \pm 48.54$ & $98.6 \pm 61.74$ \\
\hline $\begin{array}{l}\text { Wake After } \\
\text { Sleep Onset }\end{array}$ & $36.4 \pm 43.5$ & $43.5 \pm 11.87$ \\
\hline${ }^{t} p<.06$ & & \\
\hline
\end{tabular}

\section{DISCUSSION}

\subsection{Overview}

The current experiment aimed to investigate whether induction of lucid dreaming would increase the experience of positive dreams and positive waking mood. This aim was assessed by exploring the data from high and low lucidity groups (between-subjects) and from exploring individuals' highest and lowest lucidity nights (within-subjects). The results indicated that for both within and between-subjects analyses, higher lucidity was associated with more positive waking mood. Higher lucidity was also associated with more positive dream content and sensory experience in dreams, suggesting that lucidity is associated with increased vividness of dreams. No relationship was found between lucidity and subjective sleep quality. Overall, these findings suggest that lucid dreams can increase positive waking mood without deteriorating subjective sleep quality, providing valuable implications for lucid dreaming as a possible intervention or well-being practice.

We also explored whether the extent to which participants practiced induction techniques directly correlated with lucidity, although we found no relationship between the number of reality checks or minutes of MILD/WBTB techniques and lucidity. We piloted the use of a wearable headband to measure sleep, although we had a small sample with adequate data for analysis $(n=5)$. In this sample, there was no significant relationship found between lucidity and minutes of sleep stages, minutes of wake after sleep onset, or total sleep time, although high lucid nights had nearly twice as much REM sleep as low lucid nights.

\subsection{Lucidity and Positive Waking Mood}


The main finding from the current experiment indicated that higher levels of lucidity increased ratings of positive waking mood. For the between-subjects comparison, the results could possibly be explained by individual differences, that perhaps certain participants were naturally more positive, imaginative (Schredl \& Erlacher, 2004) and able to achieve lucidity. However, our within-subjects comparison additionally showed that nights with higher lucidity were associated with more positive waking mood. This is a promising addition to the lucid dreaming literature, as individual differences cannot account for this distinction, suggesting that lucidity itself is responsible for the increases in positivity. An alternative possibility that we did not test for could be that nighttime mood independently predicts morning mood, with intervening dream quality covarying within this relationship. In our study, positive valence and sensory vividness of dreams were found to be related to lucidity, in line with claims that lucid dreams are characterized by generally intensified imagery of a positive valence (Carr \& Nielsen, 2017). Nevertheless, the surrounding literature on this topic is inconsistent. Some researchers state that the majority of laboratory induced lucid dreams are emotionally neutral, rather than positive (Voss et al., 2013; Voss et al., 2014). However, links between lucidity and positivity in naturalistic sleep environments are arguably of the most significance when seeking to apply lucid dream induction as an intervention in real-life settings. Determining whether lucid dreaming has lasting impacts on mood (here only immediate morning mood is assessed), or whether morning mood mediates other long-term outcomes in lucid dreaming interventions, remains an important area for future research.

In contrast, some researchers claim that frequent and deliberate long-term lucid dream induction can increase negative psychopathologies, rather than reducing them (Aviram \& Soeffer-Dudek, 2018). In particular, a symptom labelled as dissociation, in which one distances themselves from reality to avoid emotional pain, has been shown to increase with lucid dreaming practice (Aviram \& Soeffer-Dudek, 2018). This conflicting evidence (Taitz, 2011; Aviram \& Soeffer-Dudek, 2018; Windt \& Voss, 2018) raises some questions over the suitability of lucid dream induction as a nightmare intervention, but perhaps it would be suitable for those who do not experience dissociative symptoms, as other symptoms such as stress, depressive feelings and schizotypy were not increased by lucid dream induction (Aviram \& Soeffer-Dudek, 2018). Indeed, there is a larger body of research in which lucid dream induction was used to successfully reduce the negative emotional intensity and frequency of nightmares (Zak et al., 2010). While distress due to nightmares is clinically significant and associated with psychopathology, it is possible that the positive mood 
associated with lucid dreams may have cumulative beneficial impacts on an individual over time. At the same time, nightmare sufferers have reported that increased feelings of control over dream content helped to reduce nightmare distress and provided relief from negative emotions (Harb et al., 2016; Rak et al., 2015; Scarpelli et al., 2019). Other studies suggest that lucid dreams allows sufferers to empower themselves, and have been linked to increases in self-confidence and better mental health (Doll, Gittler \& Holzinger, 2009; Holzinger, Klosch \& Saletu, 2015). In addition, lucid dreams can act relatively quickly (in some cases after one intervention session; Zadra \& Pihl, 1997; Zadra, 1990) implicating lower costs than longer-term treatments. A recent review of the evidence (Macêdo et al., 2019) concluded that lucid dream induction is a promising treatment for nightmares, but that more research is necessary for clinical guidelines to be established.

\subsection{Induction techniques, sleep quality, and lucidity levels}

The findings from the current experiment suggested that increasing the number of reality checks and minutes of MILD/WBTB techniques did not correlate with increased lucidity. These findings contrast with that of other researchers (Aspy et al., 2017). On considering the techniques separately, the use of the reality check technique on its own has yielded mixed results (Stumbrys et al., 2012), with others similarly finding that there was no significant link between reality checking and lucidity (Taitz, 2011). It's possible that our sample size was too low, as another induction study recruited 420 participants (Aspy et al., 2017) in comparison to 20 in our study. In addition, participants may not have been motivated enough to wake up in the early hours and perform the MILD technique, which has been noted as an issue in student populations (Taitz, 2011), who were participants in the current experiment. The use of portable headbands in our study placed limitations on sample size; it is likewise possible that the addition of the portable headband complicated the procedure for participants, distracting from the focus of the MILD technique.

The current experiment was inadequate to test our hypothesis that lucidity was associated with higher REM sleep, because of the large amount of data loss (see Limitations). Nevertheless, descriptively we found that REM sleep duration was nearly twice as high on the highest compared to the lowest lucid night. These results are inconclusive, especially given the small sample size, and encourage further research into the link between REM sleep and lucidity. Neverthelss, in regards to subjective sleep quality, our results indicated that reported sleep quality did not significantly differ or correlate between high and low lucidity, 
suggesting that lucidity did not disturb sleep subjectively, a finding paralleled by Aspy et al. (2017).

Finally, the overall lucidity levels in our study as measured by the lucidity questionnaire were relatively low. Given that there were 19 items on the lucidity questionnaire each rated according to the options $0=$ not at all, $1=$ a little, $2=$ moderately, $3=$ pretty much, and $4=$ very much, scoring high on a couple items might still give a relatively low score overall (the average lucidity score for the high night was 1.4, with a maximum of 2.6). The lucidity questionnaire has a variety of items that range from rating the extent of simple insight or thought in a dream, such as 'I was aware of differences to the waking state' or 'I thought about different possibilities of what I could to', to items rating more complex dream control, including 'I had full control of my dream body' or 'I changed the dream scene in the way I wanted'. See Table 4 for examples of dreams with varying levels of lucidity. The highest rated lucid dream shows clear evidence of insight although there is no indication of controlling the dream, which could explain why their overall lucidity score is still only 2.6 . It is worth mentioning that we never instructed participants in any elements of dream control, rather participants were only practicing the intention to realize they were dreaming. Nevertheless it is promising that even the small increase in lucidity measured here seems to be associated with more positive waking mood.

Table 4. Examples of dream reports at varying levels of lucidity

\begin{tabular}{|l|l|}
\hline $\begin{array}{l}\text { Lucidity } \\
\text { Score }\end{array}$ & $\begin{array}{l}\text { Dream Report } \\
.05\end{array}$ \\
$\begin{array}{l}\text { We were staying in a big old fashioned house, and were given a key each for the } \\
\text { house [...]. Through my door, there was a train track floating on water and a } \\
\text { man had fallen in, so I went in and pulled him down over the water while the } \\
\text { train went over our heads. Then we went back to the surface but I was back in } \\
\text { the old fashioned house being chased by the housekeeper. It felt like I was just } \\
\text { part of a story, I didn't know I was in a dream, was just there. }\end{array}$ \\
\hline .4 & $\begin{array}{l}\text { I was hiding from the bad guys who had some kind of bad plot/ trying to destroy } \\
\text { something. [...] Then I had to rescue this boy who was dead from the sea but } \\
\text { then he wasn't actually dead but the spies were hunting for him. [...] I must } \\
\text { have been aware I was dreaming without consciously realizing it as I knew that I }\end{array}$ \\
\hline
\end{tabular}




\begin{tabular}{|l|l|}
\hline \multirow{1}{*}{1.5} & $\begin{array}{l}\text { was able to breathe underwater, however I never thought that that was because } \\
\text { of a dream I just never thought beyond the point that I could do it. }\end{array}$ \\
$\begin{array}{l}\text { I had to find a way out on a cliff with some people including my brother who } \\
\text { was on the other side, [I had] to pass from } 2 \text { big and scary dogs. I stopped and I } \\
\text { said oh I can scream as much as I want so he will hear me. I think I knew I was } \\
\text { dreaming but not completely sure... because everything was happening around } \\
\text { me without me changing any scenery. }\end{array}$ \\
\hline 2.6 & $\begin{array}{l}\text { Dreamt I was a hostage on a riverboat (really bizarre) but managed to get away. } \\
\text { Felt scared at times and then happy when I escaped. [...] I was aware it wasn't } \\
\text { totally real and that at some point I would wake up. At one point I was in a river } \\
\text { but knew I wouldn't wake up wet. }\end{array}$ \\
\hline
\end{tabular}

\subsection{Limitations}

The current experiment had several limitations. First, positive emotion could have resulted from a sense of achievement over attaining lucidity, perhaps distorting the levels of positive emotion reported. This may have been exacerbated by opportunity sampling, in that participants responded to an advertisement to a study on lucid dreaming, and thus may have already held an interest in lucid dreaming. Overall, these points lower the generalisability of the current findings to the general population.

Second, the amount of sleep data obtained from the current study was very low, with only 5 participants producing quality recordings that could be matched to their highest and lowest lucidity night. A major difficulty was that participants were inconsistent in filling in the dream diary (on the appropriate date) and wearing the headband each night so that the data could be matched up. If a participant completed two diary entries on the same date (e.g. one entry for yesterday's dream and mood, and one entry for today's dream and mood), we could not definitively match each entry to the headband recording dates, and therefore we excluded these sleep data from analyses. Given that this was a first pilot use of portable headbands, the design could be improved for future research to ensure adequate recordings. Given the complexity of the procedures for participants to practice at home, further incentives may be needed, such as mobile phone reminders (to fill in the diary each morning, to charge the headband, to wear the headband) or higher payment. Another solution would be to make use 
of the remote access feature of ZMax headbands to ensure participants are recording properly each night.

\subsection{Recommendations for Future Research}

Future research on lucid dreaming and its applications would benefit from continuing to recruit larger and more representative samples by finding participants from different backgrounds (rather than mostly students; Schredl \& Noveski, 2018). It would also be valuable to use non-priming language in the information given before the experiment has begun (Stumbrys, Erlacher, Johnson \& Schredl, 2014). In this way, relationships unearthed between lucidity, induction techniques and mood can be more clearly established as they are less likely to be confounded by bias surrounding positive feelings towards achieving lucidity. In the current study, it is possible that the positive mood experienced following a lucid dream was due in part to a sense of achievement, that participants felt good because they had succeeded with the techniques. Another valuable avenue for future research would be to ask participants to practice the techniques for a longer period of time, so that they have the potential to become increasingly habitual, as some participants reported that they forgot to practice techniques in their answers for their dream diary. Indeed, Stumbrys \& Erlacher (2016) point out the need for increasing the number of longitudinal studies concerning lucid dreams and impact on mood across a number of weeks, rather than just one day's waking mood.

Finally, future research could benefit from exploring methods to control or influence the content of lucid dreams, perhaps establishing action plans of what an individual would like to do or how to confront negative dreams if they occur. This is likely necessary as some researchers found that a lack of control experienced during lucidity can sometimes worsen nightmares (Zadra, 1990). Alternatively, meditation could be utilised before sleep and in conjunction with induction techniques, so that dreamers are at less risk of entering lucid dreams in a stressed or anxious state; such exercises have been shown in themselves to improve psychological wellbeing (Lee \& Kuiken, 2015). These methods could prime the experience of positive lucid dreams, which is important considering that inducing frequent lucid dreams that lack in positive emotional intensity carries the possibility of negative longterm consequences relating to psychopathology (Aviram \& Soeffer-Dudek, 2018).

\subsection{Conclusions}


The current experiment aimed to investigate whether dream lucidity was associated with the valence of dream content or waking mood, whilst also assessing any links between lucidity and sleep quality. The present findings that lucidity was associated with increased positive dream content and positive waking mood, without decreasing subjective sleep quality, support its potential for improving wellbeing and treating nightmares. Future research investigating objective sleep correlates of lucid dreaming and long-term impacts of lucid dreaming on mood are encouraged. 


\section{REFERENCES}

Agargun, M. Y., Boysan, M., \& Hanoglu, L. (2004). Sleeping position, dream emotions, and subjective sleep quality. Sleep and Hypnosis, 6, 8-13.

Aspy, D. J., Delfabbro, P., Proeve, M., \& Mohr, P. (2017). Reality testing and the mnemonic induction of lucid dreams: Findings from the national Australian lucid dream induction study. Dreaming, 27(3), 206.

Aviram, L., \& Soffer-Dudek, N. (2018). Lucid dreaming: Intensity, but not frequency, is inversely related to psychopathology. Frontiers in psychology, 9, 384.

Belicki, K. (1992). Nightmare frequency versus nightmare distress: Relations to psychopathology and cognitive style. Journal of abnormal psychology, 101(3), 592.

Berry, R. B., Brooks, R., Gamaldo, C. E., Harding, S. M., Marcus, C., \& Vaughn, B. V. (2012). The AASM manual for the scoring of sleep and associated events. Rules, Terminology and Technical Specifications, Darien, Illinois, American Academy of Sleep Medicine, 176, 2012.

Carr, M., \& Nielsen, T. (2015). Daydreams and nap dreams: Content comparisons. Consciousness and cognition, 36, 196-205.

Carr, M., \& Nielsen, T. (2017). A novel differential susceptibility framework for the study of nightmares: Evidence for trait sensory processing sensitivity. Clinical psychology review, 58, 86-96.

Carr, M., Blanchette-Carrière, C., Solomonova, E., Paquette, T., \& Nielsen, T. (2016).

Intensified daydreams and nap dreams in frequent nightmare sufferers. Dreaming, 26(2), 119.

Doll, E., Gittler, G., \& Holzinger, B. (2009). Dreaming, Lucid Dreaming and Personality. International Journal of Dream Research, 2(2), 52-57.

Gieselmann, A., Ait Aoudia, M., Carr, M., Germain, A., Gorzka, R., Holzinger, B., ... \& Nadorff, M. R. (2019). Aetiology and treatment of nightmare disorder: State of the art and future perspectives. Journal of Sleep Research, e12820.

Harb, G. C., Brownlow, J. A., \& Ross, R. J. (2016). Posttraumatic nightmares and imagery rehearsal: The possible role of lucid dreaming. Dreaming, 26(3), 238.

Holzinger, B., Klösch, G., \& Saletu, B. (2015). Studies with lucid dreaming as add-on therapy to Gestalt therapy. Acta Neurologica Scandinavica, 131(6), 355-363.

Konkoly, K., \& Burke, C. T. (2019). Can learning to lucid dream promote personal growth?. Dreaming, 29(2), 113-126.

Kuiken, D. (1995). Dreams and feeling realization. Dreaming, 5(3), 129.

LaBerge, S. P. (1980). Lucid dreaming as a learnable skill: A case study. Perceptual and Motor Skills, 51(3_suppl2), 1039-1042. 
LaBerge, S. P., Nagel, L. E., Dement, W. C., \& Zarcone Jr, V. P. (1981). Lucid dreaming verified by volitional communication during REM sleep. Perceptual and motor skills, 52(3), 727-732.

LaBerge, S., Phillips, L., \& Levitan, L. (1994). An hour of wakefulness before morning naps makes lucidity more likely. NightLight, 6(3), 1-4.

LaBerge, S., \& Rheingold, H. (1991). Exploring the world of lucid dreaming (p. 17). New York: Ballantine Books.

Lee, M. N., \& Kuiken, D. (2015). Continuity of reflective awareness across waking and dreaming states. Dreaming, 25(2), 141.

Macedo, T. C. F., Ferreira, G. H., Almondes, K. M. D., Kirov, R., \& Mota-Rolim, S. A. (2019). My dream, my rules: can lucid dreaming treat nightmares? Frontiers in Psychology, $10,2618$.

Mota-Rolim, S. A., Pavlou, A., Nascimento, G., Araujo, J. F., \& Ribeiro, S. (2019). Portable devices to induce lucid dreams-are they reliable?. Frontiers in neuroscience, 13, 428.

Rak, M., Beitinger, P., Steiger, A., Schredl, M., \& Dresler, M. (2015). Increased lucid dreaming frequency in narcolepsy. Sleep, 38(5), 787-792.

Scarpelli, S., Bartolacci, C., D'Atri, A., Gorgoni, M., \& De Gennaro, L. (2019). The Functional Role of Dreaming in Emotional Processes. Frontiers in psychology, 10, 459.

Schädlich, M., \& Erlacher, D. (2012). Applications of lucid dreams: An online study. International Journal of Dream Research, 5(2), 134-138.

Schredl, M., \& Noveski, A. (2018). Lucid dreaming: A diary study. Imagination, Cognition and Personality, 38(1), 5-17.

Schredl, M., Rieger, J., \& Göritz, A. S. (2018). Measuring lucid dreaming skills: A new questionnaire (LUSK). International Journal of Dream Research. 11(1), 54-61.

Soffer-Dudek, N. (2020). Are Lucid Dreams Good for Us? Are We Asking the Right Question? A Call for Caution in Lucid Dream Research. Frontiers in Neuroscience, 13, 1423.

Spoormaker, V. I., \& Van Den Bout, J. (2006). Lucid dreaming treatment for nightmares: a pilot study. Psychotherapy and psychosomatics, 75(6), 389-394.

Stumbrys, T., \& Erlacher, D. (2016). Applications of lucid dreams and their effects on the mood upon awakening. International Journal of Dream Research, 9(2), 146-150.

Stumbrys, T., Erlacher, D., Johnson, M., \& Schredl, M. (2014). The phenomenology of lucid dreaming: An online survey. The American journal of psychology, 127(2), 191-204.

Stumbrys, T., Erlacher, D., Schädlich, M., \& Schredl, M. (2012). Induction of lucid dreams: A systematic review of evidence. Consciousness and Cognition, 21(3) 1456-1475. 
Stumbrys, T., Erlacher, D., \& Schredl, M. (2013). Testing the involvement of the prefrontal cortex in lucid dreaming: a tDCS study. Consciousness and cognition, 22(4), 1214-1222.

Taitz, I. Y. (2011). Learning Lucid Dreaming and its Effect on Depression in Undergraduates. International Journal of Dream Research, 117-126.

Voss, U., Holzmann, R., Hobson, A., Paulus, W., Koppehele-Gossel, J., Klimke, A., \& Nitsche, M. A. (2014). Induction of self awareness in dreams through frontal low current stimulation of gamma activity. Nature Neuroscience, 17(6), 810-812.

Voss, U., Holzmann, R., Tuin, I., \& Hobson, A. J. (2009). Lucid dreaming: a state of consciousness with features of both waking and non-lucid dreaming. Sleep, 32(9), 11911200 .

Voss, U., Schermelleh-Engel, K., Windt, J., Frenzel, C., \& Hobson, A. (2013). Measuring consciousness in dreams: The lucidity and consciousness in dreams scale. Consciousness and Cognition, 22(1), 8-21.

Watson, D., Clark, L. A., \& Tellegan, A. (1988). Development and validation of brief measures of positive and negative affect: The PANAS scales. Journal of Personality and Social Psychology, 54(6), 1063-1070.

Windt, J. M., \& Voss, U. (2018). Spontaneous thought, insight, and control in lucid dreams. In The Oxford Handbook of Spontaneous Thought: Mind-Wandering, Creativity, and Dreaming (pp. 385-410). Oxford University Press.

Zadra, A. L. (1990). Lucid dreaming, dream control, and the treatment of nightmares. In Seventh Annual Conference of the Association for the Study of Dreams, Chicago.

Zadra, A. L., \& Pihl, R. O. (1997). Lucid dreaming as a treatment for recurrent nightmares. Psychotherapy and Psychosomatics, 66(1), 50-55.

Zadra, A. (1996). Recurrent dreams and their relation to life events and well-being. In D. Barrett (Ed.), Trauma and dreams (pp. 231-247). Harvard University Press.

Zak, R. S., Auerbach, S. H., Casey, K. R., Chowdhuri, S., Karippot, A., Maganti, R. K., ... \& Morgenthaler, T. I. (2010). Best practice guide for the treatment of nightmare disorder in adults. Journal of clinical sleep medicine, 6(04), 389-401. 